\title{
Article
}

\section{Does exercise training prescription based on estimated heart rate training zones exceed the ventilatory anaerobic threshold in patients with coronary heart disease undergoing usual-care cardiovascular rehabilitation?: A United Kingdom perspective}

Pymer, Sean, Nichols, Simon, Prosser, Jon, Birkett, Stefan, Carroll, Sean and Ingle, Lee

Available at http://clok.uclan.ac.uk/28581/

Pymer, Sean, Nichols, Simon, Prosser, Jon, Birkett, Stefan ORCID: 0000-00030422-6843, Carroll, Sean and Ingle, Lee (2020) Does exercise training prescription based on estimated heart rate training zones exceed the ventilatory anaerobic threshold in patients with coronary heart disease undergoing usual-care cardiovascular rehabilitation?: A United Kingdom perspective. European Journal of Preventive Cardiology, 27 (6). pp. 579-589. ISSN 2047-4873

It is advisable to refer to the publisher's version if you intend to cite from the work. http://dx.doi.org/10.1177/2047487319852711

For more information about UCLan's research in this area go to http://www.uclan.ac.uk/researchgroups/ and search for <name of research Group>.

For information about Research generally at UCLan please go to http://www.uclan.ac.uk/research/

All outputs in CLoK are protected by Intellectual Property Rights law, including

CLoK

Central Lancashire online Knowledge www.clok.uclan.ac.uk

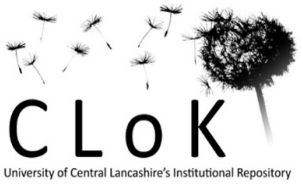




\section{CLoK}

Central Lancashire online Knowledge www.clok.uclan.ac.uk 
1 Does exercise training prescription based on estimated heart rate training zones exceed

2 the ventilatory anaerobic threshold in patients with coronary heart disease undergoing

3 usual-care cardiovascular rehabilitation?: A United Kingdom perspective.

4 Sean Pymer ${ }^{1}$

5 Simon Nichols ${ }^{2 *}$

6 Jonathon Prosser ${ }^{3}$

7 Stefan Birkett ${ }^{4}$

8 Sean Carroll ${ }^{5}$

$9 \quad$ Lee Ingle 5

10

11 Corresponding Author: *Dr Simon Nichols, Centre for Sport and Exercise Science, Sheffield

12 Hallam University, Sheffield, UK (‥J.Nichols@shu.ac.uk)

13 Institutions:

$14{ }^{1}$ Academic Vascular Surgical Unit Hull York Medical School, Hull, UK.

$15{ }^{2}$ Centre for Sport and Exercise Science, Sheffield Hallam University, Sheffield, UK

$16{ }^{3}$ Atrium Health, Centre for Exercise and Health, Coventry, UK

$17{ }^{4}$ School of Sport \& Wellbeing, University of Central Lancashire, Preston, UK

$18{ }^{5}$ Department of Sport, Health \& Exercise Science, University of Hull, Hull, UK.

19 Funding - Sean Pymer is funded by a University of Hull PhD scholarship.

20 Word Count 3,128 (excluding abstract, tables, figures, references). 
1 Abstract

2 Background: In the United Kingdom (UK), exercise intensity is prescribed from a fixed percentage range (\% heart rate reserve; \%HRR) in cardiac rehabilitation (CR) programmes. We aimed to determine the accuracy of this approach by comparing it with an objective, threshold-based approach incorporating the accurate determination of ventilatory anaerobic threshold (VAT). We also aimed to investigate the role of baseline cardiorespiratory fitness status, and exercise testing mode dependency (cycle $v$ treadmill ergometer) on these relationships.

9 Design/Methods: A maximal cardiopulmonary exercise test was conducted on a cycle ergometer or a treadmill before and following usual-care circuit training from two separate

11 CR programmes from a single region in the UK. The heart rate corresponding to VAT was compared to current heart rate-based exercise prescription guidelines.

Results: We included 112 referred patients (61 years [59-63]; body mass index $29 \mathrm{~kg} \cdot \mathrm{m}^{-2}$ [29-30]; 88\% male). There was a significant but relatively weak correlation ( $r=0.32 ; P=0.001)$ between measured and predicted \%HRR, and values were significantly different from each other $(P=0.005)$. Within this cohort, we found that $55 \%$ of patients had their VAT identified outside of the $40-70 \%$ predicted HRR exercise training zone. In the majority of participants (45\%), the VAT occurred at an exercise intensity $<40 \%$ HRR). Moreover, $57 \%$ of patients with low levels of cardiorespiratory achieved VAT at $<40 \%$ HRR. Whereas, $30 \%$ of patients with higher fitness achieved their VAT at $>70 \%$ HRR. VAT was significantly higher on the treadmill than the cycle ergometer $(P<0.001)$.

Conclusion: In the UK, current guidelines for prescribing exercise intensity are based on a fixed percentage range. Our findings indicate that this approach may be inaccurate in a large proportion of patients undertaking CR.

Word Count: 274 words

Key words: cardiac rehabilitation, exercise prescription, cardiorespiratory fitness, ventilatory anaerobic threshold. 
2 Cardiovascular rehabilitation $(\mathrm{CR})$ is a multi-disciplinary secondary prevention programme

3 that has been shown to contribute to reduced hospital admissions, and improvements in

4 patient quality of life, following a cardiac event.(1-4) Historically, a $1 \%$ improvement in peak

5 oxygen uptake $\left(\mathrm{VO}_{2 \text { peak }}\right)$ resulting from exercise-based $\mathrm{CR}$, was thought to confer a $2 \%$

6 reduction in premature mortality.(5) Similarly, every $3.5 \mathrm{ml} \cdot \mathrm{kg}^{-1} \cdot \mathrm{min}^{-1}$ increment in $\mathrm{VO}_{2 \text { peak }}$

7 has been associated with a $12-13 \%$ survival benefit $(6,7)$ in men referred for exercise

8 testing. Therefore, it is essential that the prescribed dose of exercise is sufficient to

9 stimulate improvements in $\mathrm{VO}_{2 \text { peak }}$ following $\mathrm{CR}$. Recent systematic reviews and meta-

10 analyses have shown that increased exercise intensity is an important factor in achieving

11 superior outcomes in patients with cardiovascular disease. $(8,9)$

12 The prescribed dose of exercise can be influenced by manipulating exercise frequency,

13 duration, type/mode, and/or intensity [exercise dose].(10) In the United Kingdom (UK),

14 current long-term exercise training guidelines for patients undertaking $C R$, recommend

15 exercise training intensities between $40-70 \%$ heart rate reserve (HRR), oxygen uptake

16 reserve $\left(\mathrm{VO}_{2} \mathrm{R}\right)$, or a Borg rating of perceived exertion (RPE) between 11-14.(11, 12) Both

17 continuous and interval training at an objective physiological threshold has been shown to have a

18 beneficial impact by improving $\mathrm{VO}_{2}$ peak.(13) Training at or above the ventilatory anaerobic

19 threshold (VAT), often referred to as the first ventilatory threshold (VT1), indicates the

20 point above which, further increments in work rate are increasingly supplemented through

21 anaerobic metabolism.(14-17) Despite being associated with mild metabolic

22 perturbations, $(16,17)$ regular exercise bouts conducted at work rates equivalent to VAT are

23 well tolerated,(18) and induce physiological adaptation leading to improved

24 cardiorespiratory fitness (CRF) and other cardiovascular risk factors. $(19,20)$ However, whilst 
1 work rates corresponding to VAT may represent a minimum intensity needed to improve

2 CRF, metabolic gas equipment and calibrated ergometers are often not available in a CR

3 setting in the UK. Prescribing exercise as a percentage of measured HRR, or most typically

4 estimated HRR, is often a more practical and realistic alternative in UK cardiac rehabilitation

5 settings.(10)

6 The $40 \%$ HRR threshold is cited as the lowest effective exercise intensity for improving CRF

7 in patients undertaking CR. $(10,12)$ The individual VAT is widely accepted to occur between

$8 \quad 45-65 \%$ HRR in healthy and cardiac patients,(8) with lower values reported in patients with a

9 chronic cardiovascular disease.(10) However, the distribution of VAT values, and its relation

10 to exercise capacity, is unclear in patients undertaking CR. How commonly VAT occurs

11 within discrete exercise intensity ranges is also under-reported in patients with coronary

12 artery disease. Tan et al (21) showed that the mean VAT was equal to $82 \%$ of maximal heart

13 rate (HR), in 19 cardiac patients referred for a cardiopulmonary exercise test (CPET) prior to

$14 \mathrm{CR},(21)$. However, the mode of exercise testing may also influence when an individual's VAT

15 occurs.

16 In the UK, the mode of exercise testing varies between CR programmes. This means that a

17 patient's exercise prescription could be based on a number of different submaximal exercise

18 tests, including the 6-min walk test, incremental shuttle walk test, step test, or cycle

19 ergometry. The differing metabolic responses to cycling compared with walking may affect a

20 patient's peak oxygen uptake $\left(\dot{\mathrm{V}}_{2 \text { peak }}\right)$, and the occurrence of VAT. This, in turn, may

21 significantly affect the accuracy of exercise intensity prescription. These issues have not

22 been addressed sufficiently within UK guidelines for exercise prescription in CR

23 programmes. This information may help practitioners to optimise a patient's initial exercise 
1 prescription and maximise the improvements associated with exercise training

2 programmes. This is especially important when the frequency and duration of CR sessions

3 are finite. We aimed to determine the accuracy of the standard UK approach for prescribing

4 exercise in patients undertaking CR by comparing it with objective measures of exercise

5 prescription, namely $\dot{\mathrm{V}}_{2 \text { peak }}$ and VAT. Secondary aims were to determine how exercise

6 modality (exercise testing with cycle versus treadmill ergometer), and baseline levels of CRF

7 affected the concordance of VAT and HRR measures.

9 Methods

10 Data was collated from the baseline assessment of two separate cohorts who undertook a

11 maximal effort CPET to volitional exhaustion prior to commencing a CR programme. The

12 methods for these studies have previously been reported.(22, 23) Ethical approval was

13 provided by the Yorkshire and Humber - Sheffield National (12/YH/0072) and Humber

14 Bridge NHS (12/YH/0278) Research Ethics Committees. Briefly, patients were recruited

15 following a referral to CR for angina, myocardial infarction (MI), coronary artery bypass graft

16 ( $C A B G)$, or percutaneous coronary intervention ( $\mathrm{PCl})$. Patients attended a baseline study

17 assessment, where written informed consent was obtained. CPET was conducted on a cycle

18 ergometer following a $25 \mathrm{~W}$ incremental protocol, or on a treadmill following the modified

19 Bruce protocol,(24) adopting previously outlined test termination and maximal effort

20 criteria. $(15,25)$ Breath-by-breath metabolic gas exchange data were collected using an

21 Innocor (Innovision, Glamsbjerg, Denmark) or Oxycon-Pro metabolic cart (Jaeger,

22 Hoechburg, Germany), respectively, which were calibrated according to manufacturers'

23 instructions and current recommendations.(26) Peak values were averaged over the final 30 
1 seconds of the CPET. VO $\mathrm{VO}_{2 \text { peak }}$ was reported in absolute values $\left(\mathrm{L} \cdot \mathrm{min}^{-1}\right)$ and standardised to each patient's body mass $\left(\mathrm{ml} \cdot \mathrm{kg}^{-1} \cdot \mathrm{min}^{-1}\right)$. Individualised VAT was independently determined by two investigators (using the average of the middle five of every seven breaths plotted in the V-slope method, and verified using the ventilatory equivalents. $(14,27)$ Where

5 investigators reported different VAT values, a third reviewer was consulted and the

6 threshold value agreed by consensus. The VAT was reported in L. $\mathrm{min}^{-1}$ and $\mathrm{ml} \cdot \mathrm{kg}^{-1} \cdot \mathrm{min}^{-1}$ and expressed as a percentage of directly-determined and predicted $\mathrm{VO}_{2 \text { peak. }}$ (28) The HR at VAT was then established and reported as a ratio of HRmax and HRR determined from CPET, and as a ratio of predicted HRmax and HRR with relevant adjustment for the effects of betablockade on maximal heart rates as follows [10]):

To characterise where a patients VAT occurred in relation to established training zones, the VAT values were categorically assigned to exercise intensity groups of $<40 \%, 40-49 \%, 50-$ $59 \%, 60-69 \%, 70 \%$, and $>70 \%$ of measured, and predicted HRR. Adjustment for $\beta$-blockades were made where appropriate,(12). We assessed how many patients had a VAT that occurred within the exercise training intensity ranges recommended by UK CR guidelines, namely $40-70 \%$ HRR, or an RPE between 11-14.(11, 12) Patients were sub-categorised according to individual CRF levels as low ( $<5$ METs for women, $<6$ METs for men), moderate (5<7 METs for women, $6<8$ METs for men), and high CRF ( $\geq 7$ METs for women, $\geq 8$ METs for men), based on exercise capacity (MET) thresholds derived from the international literature and previously applied to cardiac patients in the UK.(29) These sub-groups were then 
1 categorised based on the HRR zone that the individualised VAT occurred within. We also

2 conducted sub-analyses on patients who undertook their CPET either on a treadmill or cycle

3 ergometer.

Data analysis

6 Statistical analysis was conducted using SPSS version 24 (IBM, NY, USA). When data was not

7 normally distributed, normalisation of the distribution was attempted using $\log _{10}$

8 transformation. Logarithmically transformed data was analysed in its transformed state and

9 reported as an arithmetic mean to allow for meaningful interpretation. Normally distributed

10 and transformed data were analysed using a univariate general linear model with

11 significance set at arbitrary level $(P<0.05)$, and is presented as mean $(95 \%$ confidence

12 intervals), and partial-eta squared $\left(\eta_{p}^{2}\right)$ effect sizes, with $0.01,0.06$, and 0.14 denoting

13 small, moderate, and large effects, respectively (30). For non-normally distributed data, a

14 Mann-Whitney $\mathrm{U}$ test was conducted with median and range reported. Categorical data was

15 analysed using a Chi-squared test of independence and reported as percentage and

16 frequency. When $\geq 1$ cell had an expected value $<5$, the Fisher's exact test was used.

18 Results

19 Patient Characteristics

20 One-hundred and twelve $(n=112)$ cardiac patients were included for analysis (61.3 years

21 [59.4-63.1]; $29.3 \mathrm{~kg} \cdot \mathrm{m}^{-2}$ [28.5-30.1]; 88\% male). Forty-two patients ( $\left.n=42 ; 37.5 \%\right)$ undertook

22 their CPET on a cycle ergometer. Patients on a cycle ergometer achieved $79.1 \%$ of their

23 predicted HRmax [74.6-83.6\%], an RPE of 18 [17-18], and a peak respiratory exchange ratio 
1 (RER) of 1.02 [1.00-1.05). Seventy $(n=70)$ patients undertook CPET on a treadmill. Patients

2 conducting CPET on a treadmill achieved $82.3 \%$ [79.7-84.9\%] of predicted HRmax), an RPE of

317.8 [17.3-18.3], and a peak RER of 1.09 [1.06-1.11]). $77 \%$ and $86 \%$ of the patients

4 undergoing cycle and treadmill testing, respectively, were prescribed beta-blockers. The

5 majority of patients had a diagnosis of myocardial infarction (MI) with primary (32.5\%) or

6 elective $(28.9 \%) \mathrm{PCl}$. There was a greater prevalence of active smokers $(P=0.017)$ in those

7 that conducted a CPET on a cycle ergometer. There were significant between-group

8 differences for age $\left(P=0.012 ; \eta_{p}^{2}=0.054\right)$, and resting $\mathrm{HR}$ (mean difference $5.8 \mathrm{bpm}(95 \% \mathrm{Cl}$

9 1.0-10.5bpm) $P=0.032$; Table 1 ) between the test modality groups. 42 out of 112 patients,

10 were classified within the lower cardiorespiratory fitness group, 50 in the moderate-fit 11 group, and 20 in the high-fit group (Table 2).

VAT, HRR zones, and CRF categories

15 Measured HRR (72 $\pm 15 \mathrm{bpm}$ ) derived from maximal CPET demonstrated only a modest 16 correlation with predicted HRR (77.99 $\pm 20.42 \mathrm{bpm}$ ) (using current UK CR guidelines ( $r=0.32$;

$17 P=0.001)$. However, the directly determined and predicted HRR/peak HR variables were significantly different from each other (mean difference $=6.74 \mathrm{bpm}(95 \% \mathrm{Cl} 2.99-10.49 \mathrm{bpm})$

$19 P=0.001)$. The VAT occurred within $40-70 \%$ of directly determined HRR range in $61.6 \%$ of patients. In the remaining $38.4 \%$ of patients, $33.9 \%$ achieved their VAT at $<40 \%$ HRR, and in

$214.5 \%$ of patients, their VAT did not occur until $>70 \%$ HRR. For predicted HRR, VAT occurred within $40-70 \%$ HRR in $44.6 \%$ of patients. Of the remaining $55.4 \%$ of patients, $45.4 \%$ achieved VAT at $<40 \% \mathrm{HRR}$, and $9.8 \%$ at $>70 \%$ HRR (Table 2 ). 
1 The VAT occurred between $40-70 \%$ of predicted HRR in $21.4 \%$ of patients undertaking

2 cycling exercise. The majority (76.2\%) of patients exceeded the VAT at $<40 \%$ HRR. For

3 patients undertaking CPET on a treadmill, $58.5 \%$ of patients had a VAT that occurred

4 between $40-70 \%$ of predicted HRR, and $27.1 \%$ had a VAT that occurred at $<40 \%$ HRR.

5 Interestingly, the VAT occurred between $40-70 \%$ of predicted HRR in $35.8 \%$ of patients that

6 were categorised as having a low CRF. $57.1 \%$ of patients exceeded their VAT at $<40 \%$ of

7 their HRR. For higher-fit patients, VAT occurred between $40-70 \%$ of predicted HRR in $50 \%$ of

8 patients, at $<40 \%$ HRR in $20 \%$, and $>70 \%$ HRR for the remaining $30 \%$ of patients (Table 2 ).

9 Figure 1 shows the inter-quartile range for VAT as a percentage of predicted HRR, based on

10 CRF category, and exercise testing modality. The VAT occurred at a higher percentage of

$11 \mathrm{VO}_{2 \text { peak }}$ in patients with a higher CRF. This observation was also evident when CPET was

12 conducted on a treadmill for all CRF categories, but most apparently in the moderate and

13 high-fit groups.

Directly measured compared with predicted cardiorespiratory fitness variables

Mean $\mathrm{VO}_{2 \text { peak }}$ was not significantly different between exercise modality groups in absolute

17 units $\left(P=0.644 ; \eta_{p}^{2}=0.002\right)$, or relative to body mass $\left(P=0.359 ; \eta_{p}^{2}=0.008\right)$ (Table 3).

18 However, absolute $(P=0.027)$ and relative $(P=0.001)$ VAT was significantly different across

19 the different CRF groups. VAT occurred at a higher percentage of predicted $(P=0.003$;

$\left.20 \eta_{p}^{2}=0.08\right)$ and measured $\operatorname{VO}_{2 \text { peak }}\left(P<0.001 ; \eta_{p}^{2}=0.151\right)$, and $\operatorname{HRR}\left(P<0.001 ; \eta_{p}^{2}=0.132\right)$ in

21 patients exercising on the treadmill. Measured HRR $\left(P=0.012 ; \eta_{p}^{2}=0.056\right)$, and HR at VAT

$22\left(P=0.016 ; \eta_{p}^{2}=0.052\right)$ were significantly higher in the treadmill group. There was a significant 
1 between-group difference for predicted HRmax adjusted for $\beta$-blockade ( $P=0.003$; Table 4).

2 However, there was no difference in predicted $\operatorname{HRR}\left(P=0.863 \eta_{p}^{2}=<0.001\right)$ or $\mathrm{VO}_{2 \text { peak }}$

3 between groups $\left(P=0.815, \eta_{p}^{2}<0.001\right)$. Figures $2 \mathrm{a}$ and $2 \mathrm{~b}$ highlight individual case studies

4 which demonstrate how the predicted HRR method can either over- or under- estimate

5 individualised exercise prescription versus directly determined HRR and VAT.

6

7 Discussion

8 This study aimed to determine the accuracy of the standard UK approach for prescribing

9 exercise in patients undertaking CR. This method of determining target heart rates for

10 exercise training in cardiac patients relies largely on predictive methods for determining

11 maximal HR (including patients taking beta-blockade). We sought to compare it with a more

12 objective measure of exercise prescription, namely the VAT derived from respiratory gas

13 exchange during a maximal CPET. Our findings indicate that current UK CR exercise

14 prescription guidelines appear susceptible to substantial inaccuracy with more than half of

15 our cohort achieving a VAT outside the recommended target range of $40-70 \% \mathrm{HRR}$. We

16 found that $45 \%$ of patients had VAT identified at $<40 \%$ HRR, and in $9 \%$ of patients, VAT was

17 identified at $>70 \% \mathrm{HRR}$, suggesting that the required exercise intensity spectrum is wider

18 than the recommended $40-70$ HRR\%.

19 When considering baseline cardiorespiratory fitness, the proportion of patients whose VAT

20 occurred outside the guidelines increased. $57 \%$ of low-fit patients achieving VAT at $<40 \%$

$21 \mathrm{HRR}$, and $30 \%$ of high-fit patients achieving VAT at $>70 \% \mathrm{HRR}$, confirming that VAT occurs

22 later with increasing CRF in cardiac patients.(31) For those who achieved VAT at $<40 \% \mathrm{HRR}$, 
1 their exercise prescription may overly exceed VAT and prove too challenging, whilst for

2 those that achieve VAT $>70 \%$ HRR, their prescription is unlikely to induce a training stimulus

3 and prove too easy. We speculate that this may contribute to the $23 \%$ attrition rate recently

4 reported in UK $C R,(32)$ as some patients overly exceed their training stimulus (i.e. low fit

5 patients), which may be uncomfortable, whilst some do not reach it, thus providing minimal

6 benefit (i.e. high fit patients), both of which may cause patients to discontinue CR.

7 Therefore, a one size fits all approach, relying on predictive methods for maximal HR and

8 estimated HRR to prescribe exercise appears ineffective. Exercise prescription within cardiac

9 rehabilitation settings needs to be more accurate, patient specific and fine-tuned, ideally

10 based on ventilatory markers, actual HRR and baseline fitness category determined via

11 CPET.(33) One option could be to shift from 'range-based' to 'threshold-based' CR exercise

12 prescription, with moderate-high intensity exercise, corresponding to work rates between

13 VAT and critical power, being recommended.(17) Based on the current data, CPET would aid

14 prescription to ensure that all patients achieved VAT during CR, whilst also ensuring it is not

15 overly exceeded. This is important given that certain cardiac patients, namely those who

16 may be more deconditioned, often perform activities of daily living at levels of $\mathrm{VO}_{2}$ that

17 exceed VAT.(34) Therefore, exercising in steady-state conditions above VAT is vital for these

18 patients, but may not be possible if it is exceeded. In the late 1970s, limitations in the

19 relative percent method (i.e \%HRR) for prescribing exercise intensity were identified, with a

20 study by Katch et al showing this method failed to consider individual metabolic

21 differences,(35) yet it is still a recommended approach today.(8,10) More recent

22 investigations have proposed a more individualised exercise prescription based on

23 ventilatory thresholds to personalise individualised training load based on metabolic

24 responses. $(36,37)$ Recently, Weatherwax et al reported that in sedentary adults, 12 weeks 
1 of aerobic exercise training based on an individualised exercise prescription using VAT had a

2 greater effect on the incidence of training response compared to a standardised approach

3 using HRR. While the exact mechanisms are still not entirely understood, it is believed that

4 exercise intensity prescribed with the use of ventilatory thresholds takes into consideration

5 individual metabolic characteristics which are overlooked when using relative percent

6 methods.(38)

8 The current data also indicate that VAT is mode-dependant for the overall cohort and across

9 all three CRF categories. Similar to previous suggestions,(17) VAT occurred at around 50\%

10 HRR on the treadmill but is $12-15 \%$ lower on the cycle. A similar relation has also been

11 observed in patients with chronic heart failure.(39) This mode dependency is also evident in

12 terms of predicted HRR zones, which are adopted in most UK CR centres, with $>75 \%$ of

13 patients on a cycle ergometer achieving VAT at $<40 \%$ HRR, compared with just $27 \%$ of

14 patients exercising on a treadmill. Previous research has identified a VAT mode dependency

15 in cardiac patients based on $\mathrm{VO}_{2} .(40)$ The current results differ somewhat as they show a

16 mode dependency for patients who are yet to begin as opposed to those who have finished

17 CR. Furthermore, in the current study this mode dependency is expressed using HRR, which

18 is adopted in most CR centres, rather than $\mathrm{VO}_{2}$.

19 UK CR is provided by the state-funded National Health Service, unlike CR operating in other

20 international and EU countries,(15) the integration of CPET equipment is not currently

21 incorporated into most UK centres and may prove to be prohibitive.(41) Another possible

22 solution could be to increase the upper intensity limit of exercise prescription in line with

23 international guidelines at $80 \% \mathrm{HRR}$, especially for patients in a higher fit category. $(10,42)$ 
1 Of the 10 patients whose VAT occurred at $>70 \%$ HRR, 6 achieved VAT at $<80 \%$ HRR. This

2 suggests that increasing the upper range of exercise prescription guidelines could be helpful

3 to a small cohort of patients, and provide greater scope for training progression in those

4 that could tolerate it; aligning UK guidelines closer to those seen internationally.(43) This

5 does not however, address the issue for those who achieved VAT at $<40 \%$. A further

6 alternative to personalise exercise prescription across the whole spectrum would be to

7 identify the HR range corresponding to an RPE of 11-13, given that VAT has been shown to

8 occur around this point $(44,45)$. Submaximal testing is routinely performed in UK CR and

9 identification and utilisation of the HR between these points during testing could ensure

10 more patients are exercising at or around the VAT. One caveat to such an option is that RPE

11 is a subjective tool, meaning that appropriate anchoring of key values would be required for

12 each patient, and this would need to be applied consistently within and between each CR

13 centre in the UK.

14 To be able to confidently prescribe an individualised exercise programme in a safe and effective manner can be challenging in a cardiac population. The healthcare professional must be able to account for medication usage, presence of non-CV co-morbidities, and for example, adverse events during exercise testing. Hansen and colleagues [46] showed significant inter-clinician variance in prescribing exercise for patients with different CVDs,

19 highlighting the challenges posed. Further training and education is key, however, digital 20 resources are available to assist practitioner decision-making processes. For example, the 21 European Association of Preventive Cardiology recently developed the Exercise Prescription 22 in Everyday Practice and Rehabilitative Training (EXPERT) tool.[47] The EXPERT tool is an 23 interactive, digital training and decision support system that assists healthcare professionals 24 in prescribing clinically effective and medically safe exercise training programmes for CVD 
1 patients. The adoption of tools such as EXPERT should be more widely encouraged and

2 facilitated to support decision making processes around exercise prescription in cardiac

3 populations. The impact of their utility within clinical practice could then be audited to

4 determine changes in efficacy.

\section{Limitations}

7 The key limitation is that the two groups are made up of separate patients who varied on

8 some baseline characteristics. Ideally, all patients would have completed a CPET using both

9 modalities to reduce any individual effect.

\section{Conclusion}

12 To our knowledge, this is the first study of its kind to explore VAT in terms of prescribed HRR

13 zones for cardiac patients to identify the accuracy of current UK CR exercise prescription

14 guidelines. For a large proportion of patients, the guidelines are inaccurate with many patients achieving VAT at $<40 \% \mathrm{HRR}$, meaning their exercise prescription may be overly

16 challenging. Conversely, $30 \%$ of high-fit patients achieved VAT at $>70 \%$ HRR, meaning their

17 prescription may be too conservative to provide a stimulus. This under/over-prescription

18 may lead patients to unnecessarily discontinue their CR (see Figures 2a and 2b). Therefore,

19 for UK CR, a one size fits all approach is ineffective and a shift from predictive equations and

20 submaximal exercise tests to gold-standard CPET on entry to CR would be required to

21 improve exercise prescription. However, this may not be viable for a number of reasons,

22 meaning that adoption of less conservative guidelines could provide a solution to ensuring

23 that a larger proportion of patients achieve a training stimulus. Furthermore, although 
$1 V_{2} \mathrm{O}_{2 \text { peak }}$ did not demonstrate a mode dependency, VAT did. This suggests that it may be

2 necessary to conduct a CPET using both modalities, or tailor exercise prescription based on

3 the modality used. Future research could confirm this mode dependency for HRR at VAT in

4 cardiac patients by testing the same group of patients twice, once during each modality. 
$1 \quad$ Funding

2 This research received no specific grant from any funding agency in the public, commercial

3 or not-for-profit sectors.

4 Conflict of interest

5 The authors declare that there is no conflict of interest.

6 Author contributions

7 Both SP and SN have contributed equally to this manuscript, therefore we would like them

8 both to be acknowledged as joint first authors. SN, SC and LI contributed to the design of

9 the work. SN conducted data collection. SN, SB, SP and JP conducted data analysis and

10 drafted the manuscript. SB, JP, SC, LI critically reviewed the manuscript. All gave final approval

11 and agree to be accountable for all aspects of work ensuring integrity and accuracy.

12 
1. Abell B, Glasziou P, Hoffmann T. The Contribution of Individual Exercise Training Components to Clinical Outcomes in Randomised Controlled Trials of Cardiac Rehabilitation: A Systematic Review and Meta-regression. Sports Medicine Open. 2017;3(1):19.

2. Anderson L, Oldridge N, Thompson DR, Zwisler A-D, Rees K, Martin N, et al. Exercise-Based Cardiac Rehabilitation for Coronary Heart DiseaseCochrane Systematic Review and Meta-Analysis. Journal of the American College of Cardiology. 2016;67(1):1-12. 3. Heran BS, Chen J, Ebrahim S, Moxham T, Oldridge N, Rees K, et al. Exercise-based cardiac rehabilitation for coronary heart disease. Cochrane Database Syst Rev. 2011;7.

4. Taylor RS, Unal B, Critchley JA, Capewell S. Mortality reductions in patients receiving exercise-based cardiac rehabilitation: how much can be attributed to cardiovascular risk factor improvements? European Journal of Cardiovascular Prevention \& Rehabilitation. 2006;13(3):369-74.

5. Vanhees L, Fagard R, Thijs L, Amery A. Prognostic value of training-induced change in peak exercise capacity in patients with myocardial infarcts and patients with coronary bypass surgery. The American journal of cardiology. 1995;76(14):1014-9.

6. Kokkinos P, Manolis A, Pittaras A, Doumas M, Giannelou A, Panagiotakos DB, et al. Exercise Capacity and Mortality in Hypertensive Men With and Without Additional Risk Factors. Hypertension. 2009;53(3):494-9.

7. Myers J, Prakash M, Froelicher V, Do D, Partington S, Atwood JE. Exercise Capacity and Mortality among Men Referred for Exercise Testing. New England Journal of Medicine. 2002;346(11):793-801.

8. Pattyn N, Coeckelberghs E, Buys R, Cornelissen VA, Vanhees L. Aerobic interval training vs. moderate continuous training in coronary artery disease patients: a systematic review and meta-analysis. Sports medicine. 2014;44(5):687-700.

9. Weston KS, Wisløff U, Coombes JS. High-intensity interval training in patients with lifestyle-induced cardiometabolic disease: a systematic review and meta-analysis. Br J Sports Med. 2014;48(16):1227-34.

10. ACSM. ACSM's Guidelines for Exercise Testing and Prescription. 9th ed. Baltimore: Lippincott, Williams, \& Wilkins.; 2014.

11. Borg GA. Borg's Rating of Perceived Exertion and Pain Scales. Champaign, IL: Human Kinetics; 1998.

12. ACPICR. Standards for physical activity and exercise in the cardiovascular population. 3rd ed. Heather P, Helen B, Samantha B, John B, Laura Burgess, Keri G, et al., editors: Association of Chartered Physiotherapists in Cardiac Rehabilitation 2015.

13. Ghosh AK. Anaerobic Threshold: Its Concept and Role in Endurance Sport. Malays J Med Sci. 2004 Jan; 11(1): 24-36.

4. Beaver WL, Wasserman K, Whipp BJ. A new method for detecting anaerobic threshold by gas exchange. J Appl Physiol. 1986;60(6):2020-7.

15. Nichols $\mathrm{S}$, Taylor $\mathrm{C}$, Ingle L. A clinician's guide to cardiopulmonary exercise testing 2: test interpretation. Br J Hosp Med (Lond). 2015;76(5):281-9.

16. Ghosh AK. Anaerobic Threshold: Its Concept and Role in Endurance Sport. The Malaysian Journal of Medical Sciences : MJMS. 2004;11(1):24-36.

17. Mezzani A, Hamm LF, Jones AM, McBride PE, Moholdt T, Stone JA, et al. Aerobic exercise intensity assessment and prescription in cardiac rehabilitation: a joint position statement of the European Association for Cardiovascular Prevention and Rehabilitation, the 
American Association of Cardiovascular and Pulmonary Rehabilitation and the Canadian Association of Cardiac Rehabilitation. Eur J Prev Cardiol. 2013;20(3):442-67.

18. Ekkekakis P, Hall EE, Petruzzello SJ. Practical markers of the transition from aerobic to anaerobic metabolism during exercise: rationale and a case for affect-based exercise prescription. Preventive medicine. 2004;38(2):149-59.

19. Zheng H, Luo M, Shen Y, Ma Y, Kang W. Effects of 6 months exercise training on ventricular remodelling and autonomic tone in patients with acute myocardial infarction and percutaneous coronary intervention. Journal of rehabilitation medicine. 2008;40(9):776-9.

20. Seki E, Watanabe Y, Shimada K, Sunayama S, Onishi T, Kawakami K, et al. Effects of a phase III cardiac rehabilitation program on physical status and lipid profiles in elderly patients with coronary artery disease: Juntendo Cardiac Rehabilitation Program (J-CARP). Circulation journal : official journal of the Japanese Circulation Society. 2008;72(8):1230-4.

13 21. Tan SJJ, Allen JC, Tan SY. Determination of ideal target exercise heart rate for cardiac patients suitable for rehabilitation. Clinical cardiology. 2017;40(11):1008-12.

22. Nichols S, Nation F, Goodman T, Clark A, Carroll S, Ingle L. CARE CRCardiovascular and cardiorespiratory Adaptations to Routine Exercise-based Cardiac Rehabilitation; A study protocol for a community-based control study with criterion methods. BMJ Open. 2017.

23. Nichols S, Gleadall-Siddall D, Antony R, Clark A, Cleland J, Carroll S, et al. Estimated peak functional capacity: an accurate method for assessing change in peak oxygen consumption after cardiac rehabilitation? Clinical physiology and functional imaging. 2017.

24. Bruce RA, Kusumi F, Hosmer D. Maximal oxygen intake and nomographic assessment of functional aerobic impairment in cardiovascular disease. Am Heart J. 1973;85(4):546-62.

25. American Thoracic Society. ATS/ACCP statement on cardiopulmonary exercise testing. American journal of respiratory and critical care medicine. 2003;167(2):211.

26. Balady GJ, Arena R, Sietsema K, Myers J, Coke L, Fletcher GF, et al. Clinician's Guide to Cardiopulmonary Exercise Testing in Adults: A Scientific Statement From the American Heart Association. Circulation. 2010;122(2):191-225.

27. Mezzani A, Agostoni P, Cohen-Solal A, Corra U, Jegier A, Kouidi E, et al. Standards for the use of cardiopulmonary exercise testing for the functional evaluation of cardiac patients: a report from the Exercise Physiology Section of the European Association for Cardiovascular Prevention and Rehabilitation. European Journal of Cardiovascular Prevention \& Rehabilitation. 2009;16(3):249-67.

28. Hansen J, Sue D, Wasserman K. Predicted values for clinical exercise testing. The American review of respiratory disease. 1984;129(2 Pt 2):S49-55.

29. Taylor C, Tsakirides C, Moxon J, Moxon JW, Dudfield M, Witte KK, et al. Submaximal fitness and mortality risk reduction in coronary heart disease: a retrospective cohort study of community-based exercise rehabilitation. BMJ Open. 2016;6(6):e011125.

30. Cohen J. Statistical power analysis for the behavioral sciences. 2nd ed. ed. Hillsdale, N.J. :: L. Erlbaum Associates; 1988.

31. Xie B, Yan X, Cai X, Li J. Effects of high-intensity interval training on aerobic capacity in cardiac patients: a systematic review with meta-analysis. BioMed research international. 2017;2017.

32. Doherty P, Petre C, Onion N, Harrison A, Hemingway J, Cardy K, et al. National Audit of Cardiac Rehabilitation (NACR): Annual Statistical Report 2017. 2018.

33. Ingle L, Carroll S. Cardiac rehabilitation and exercise training. Heart. 2013;99:1298.

34. Mezzani A, Corra U, Giordano A, Colombo S, Psaroudaki M, Giannuzzi P. Upper intensity limit for prolonged aerobic exercise in chronic heart failure. Med Sci Sports Exerc. 2010;42(4):633-9. 
35. Katch V, Weltman A, Sady S, Freedson P. Validity of the relative percent concept for equating training intensity. European journal of applied physiology and occupational physiology. 1978;39(4):219-27.

4 36. Dalleck LC, Haney DE, Buchanan CA, Weatherwax RM. Does a personalised

5 exercise prescription enhance training efficacy and limit training unresponsiveness? A

6 randomised controlled trial. Journal of Fitness Research. 2016;5(3).

7 37. Wolpern AE, Burgos DJ, Janot JM, Dalleck LC. Is a threshold-based model a superior

8 method to the relative percent concept for establishing individual exercise intensity? a

9 randomized controlled trial. BMC Sports Science, Medicine and Rehabilitation.

$10 \quad 2015 ; 7(1): 16$.

11 38. Weatherwax RM, Harris NK, Kilding AE, Dalleck LC. Incidence of VO2max

12 Responders to Personalized vs Standardized Exercise Prescription. Medicine and science in 13 sports and exercise. 2018.

14 39. Beckers PJ, Possemiers NM, Van Craenenbroeck EM, Van Berendoncks AM, Wuyts

$15 \mathrm{~K}$, Vrints CJ, et al. Impact of exercise testing mode on exercise parameters in patients with chronic heart failure. European journal of preventive cardiology. 2012;19(3):389-95.

40. Hansen D, Dendale P, Berger J, Meeusen R. Low agreement of ventilatory threshold between training modes in cardiac patients. Eur J Appl Physiol. 2007;101(5):547-54.

41. Chatterjee S, Sengupta S, Nag M. Cardiopulmonary exercise testing: a review of techniques and applications. J Anesth Clin Res. 2013;4:340.

42. Piepoli MF, Corra U, Benzer W, Bjarnason-Wehrens B, Dendale P, Gaita D, et al. Secondary prevention through cardiac rehabilitation: from knowledge to implementation. A position paper from the Cardiac Rehabilitation Section of the European Association of Cardiovascular Prevention and Rehabilitation. Eur J Cardiovasc Prev Rehabil. 2010;17(1):117.

43. Sandercock G, Hurtado V, Cardoso F. Changes in cardiorespiratory fitness in cardiac rehabilitation patients: a meta-analysis. Int J Cardiol. 2013;167(3):894-902.

44. Ekkekakis P, Hall EE, Petruzzello SJ. Practical markers of the transition from aerobic to anaerobic metabolism during exercise: rationale and a case for affect-based exercise prescription. Preventive medicine. 2004;38(2):149-59.

45. McConnell TR, Clark III BA, Conlin NC, Haas JH. Gas exchange anaerobic threshold: implications for prescribing exercise in cardiac rehabilitation. Journal of Cardiopulmonary Rehabilitation and Prevention. 1993;13(1):31-6.

46. Hansen D, Rovelo Ruiz G, Doherty P, Iliou MC, Vromen T, Hinton S, et al. Do clinicians prescribe exercise similarly in patients with different cardiovascular diseases? Findings from the EAPC EXPERT working group survey. Eur J Prev Cardiol. 2018; 25(7):682-691.

47. Hansen D, Dendale P, Coninx K, Vanhees L, Piepoli MF, Niebauer J, et al. The European Association of Preventive Cardiology Exercise Prescription in Everyday Practice and Rehabilitative Training (EXPERT) tool: A digital training and decision support system for optimized exercise prescription in cardiovascular disease. Concept, definitions and construction methodology. Eur J Prev Cardiol. 2017; 24(10):1017-1031. 
Table 1. Clinical characteristics of patients grouped by exercise modality

Mean $(95 \% \mathrm{Cl})+=$ median and ranges

\begin{tabular}{|c|c|c|c|c|c|}
\hline Variable & Pooled (cycle and treadmill data) & Cycle & Treadmill & P-value & $\begin{array}{c}\text { Partial } \\
\text { eta- } \\
\text { squared }\end{array}$ \\
\hline $\begin{array}{c}\text { Sex } \\
\text { (male/female) }\end{array}$ & $100 / 14(87.70 \%$ male) & $40 / 4$ (90.0\% male) & $60 / 10(85.7 \%$ male $)$ & 0.411 & \\
\hline Age (years) & $61.25(95 \% \mathrm{Cl} ; 59.35$ to 63.14$)$ & $63.13(95 \% \mathrm{Cl} ; 60.75$ to 65.51$)$ & 58.25 (95\% Cl; 55.21 to 61.29$)$ & $0.012 *$ & 0.054 \\
\hline $\mathrm{BMI}\left(\mathrm{kg} / \mathrm{m}^{2}\right) \mathrm{T}$ & 29.30 (95\% Cl; 28.54 to 30.07$)$ & 30.1 (95\% Cl; 28.8 to 31.44$)$ & 28.80 (95\% Cl; 29.74 to 27.90$)$ & 0.101 & 0.024 \\
\hline $\begin{array}{l}\text { Resting SBP } \\
(\mathrm{mmHg}) \mathrm{Tr}\end{array}$ & $131.55(95 \% \mathrm{Cl} ; 127.94$ to 135.27$)$ & $139.57(95 \% \mathrm{Cl} 134.39$ to 144.95$)$ & $126.74(95 \% \mathrm{Cl} ; 122.18$ to 131.46$)$ & $0.001 * *$ & 0.099 \\
\hline $\begin{array}{c}\text { Resting DBP } \\
(\mathrm{mmHg})^{\dagger}\end{array}$ & 83 (60 to 149$)$ & 85.50 (62 to 104$)$ & 82 (60 to 149$)$ & 0.09 & \\
\hline LVEF (\%) & $55.77(95 \% \mathrm{Cl} ; 54.34$ to 57.20$)$ & 57.05 (95\%Cl; 54.35 to 59.75$)$ & $54.99(95 \% \mathrm{Cl} ; 53.35$ to 56.62$)$ & 0.167 & 0.017 \\
\hline
\end{tabular}


BMI, Body mass index. $\mathrm{kg} \cdot \mathrm{m}^{-2}$, kilogram per metre squared. SBP, systolic blood pressure. $\mathrm{mmHg}$, millimetres of mercury. DBP, diastolic blood pressure. LVEF, left ventricular ejection fraction. HR, Heart Rate. Bpm, beats per minute.

${ }^{*} P<0.05,{ }^{*} P<0.01,{ }^{* * *} P<0.001 . \dagger$, Variables are reported as median (minimum and maximum) values and analysed using a non-parametric test. Tr, transformed using $\log _{10}$ transformation and reported as arithmetic mean for meaningful interpretation. 

Table 2. The occurrence of VAT in relation to predicted HRR training zones, stratified by exercise modality and baseline CRF levels

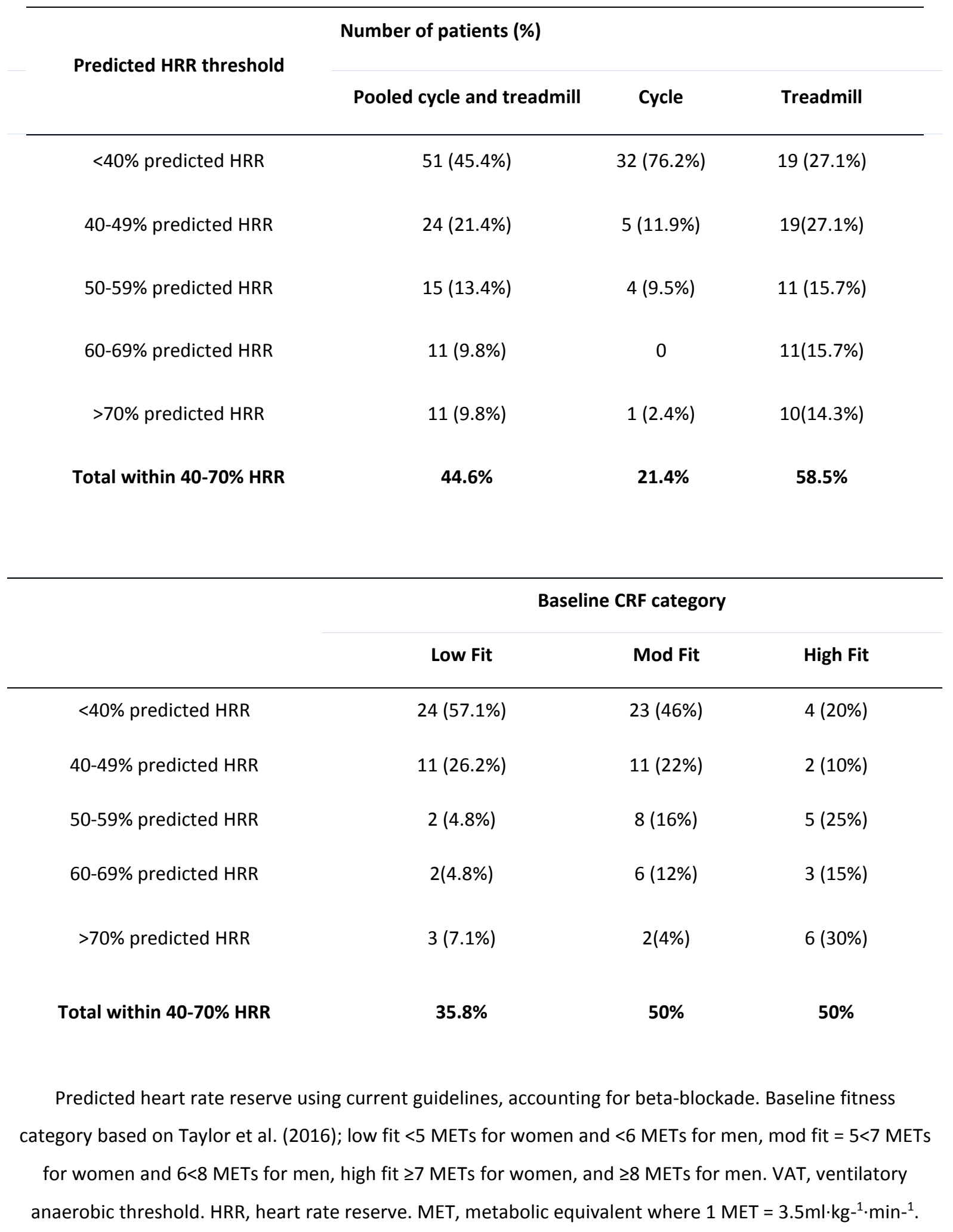


Table 3. Cardiorespiratory data based on maximal CPET in patients using cycle and treadmill exercise modalities

\begin{tabular}{|c|c|c|c|c|c|}
\hline & Pooled & Cycle & Treadmill & P-value & $\begin{array}{l}\text { Partial eta- } \\
\text { squared }\end{array}$ \\
\hline $\mathrm{VO}_{2 \text { peak }}\left(\mathrm{L} \cdot \mathrm{min}-{ }^{1}\right)$ & $\begin{array}{c}2.00(95 \% \mathrm{Cl} ; 1.88 \\
\text { to } 2.11)\end{array}$ & $\begin{array}{c}2.03(95 \% \mathrm{Cl} ; 1.82 \\
\text { to } 2.25)\end{array}$ & $\begin{array}{c}1.98(95 \% \mathrm{Cl} ; 1.83 \text { to } \\
2.12)\end{array}$ & 0.644 & 0.002 \\
\hline $\mathrm{VO}_{2 \text { peak }}\left(\mathrm{ml} \cdot \mathrm{kg}^{-1} \cdot \mathrm{min}^{-1}\right) \mathrm{Tr}$ & $\begin{array}{c}22.12(95 \% \mathrm{Cl} ; 19.8 \\
\text { to } 24.7)\end{array}$ & $\begin{array}{c}21.43(95 \% \mathrm{Cl} ; 18.0 \\
\text { to } 25.5)\end{array}$ & $\begin{array}{c}22.55(95 \% \mathrm{Cl} ; 19.7 \\
\text { to } 25.8)\end{array}$ & 0.359 & 0.008 \\
\hline $\mathrm{HRmax}(\mathrm{bpm}) \dagger$ & 137 (88 to 181$)$ & 131 (88 to 181 ) & 139 (88 to 169 ) & 0.32 & \\
\hline HRR (bpm) & $\begin{array}{c}71.5(95 \% \mathrm{Cl} ; 67.7 \\
\text { to } 75.4)\end{array}$ & $\begin{array}{c}65.1(95 \% \mathrm{Cl} ; 58.9 \\
\text { to } 71.3)\end{array}$ & $\begin{array}{c}75.43(95 \% \mathrm{Cl} ; 70.69 \\
\text { to } 80.17)\end{array}$ & $0.009 *$ & 0.061 \\
\hline $\operatorname{VAT}\left(\mathrm{ml} \cdot \mathrm{kg}^{-1} \cdot \mathrm{min}^{-1}\right) \dagger$ & 13.1 (8.2 to 29.7 ) & 13.3 (8.2 to 26.0 ) & 16.6 (8.6 to 30.0 ) & $0.001 * * *$ & \\
\hline VAT $\left(L \cdot m i n-{ }^{1}\right) \dagger$ & $1.3(0.7$ to 2.5$)$ & 1.15 (0.7 to 2.0$)$ & 1.35 (0.7 to 2.5$)$ & $0.027^{*}$ & \\
\hline HR at VAT (bpm) & $\begin{array}{c}94(95 \% \mathrm{Cl} ; 91 \text { to } \\
97)\end{array}$ & $\begin{array}{c}90 \text { (95\% Cl; } 85 \text { to } \\
94)\end{array}$ & $\begin{array}{c}97(95 \% \mathrm{Cl} ; 93 \text { to } \\
101)\end{array}$ & $0.016^{*}$ & 0.05 \\
\hline VAT ( $\%$ of $\mathrm{VO}_{2 \text { peak }}$ ) & $\begin{array}{c}67.5 \text { (95\%Cl; } 65 \text { to } \\
70)\end{array}$ & $\begin{array}{c}61.3(95 \% \mathrm{Cl} ; 58 \text { to } \\
65)\end{array}$ & $\begin{array}{c}71.1 \text { (95\%Cl; } 68 \text { to } \\
74)\end{array}$ & $<0.001 * * *$ & 0.151 \\
\hline $\begin{array}{c}\text { VAT ( } \% \text { of predicted } \\
\text { VO } \text { 2peak }^{\text {p }} \mathrm{Tr}\end{array}$ & $\begin{array}{c}56.8(95 \% \mathrm{Cl} ; 52 \text { to } \\
63)\end{array}$ & $\begin{array}{c}51.8(95 \% \mathrm{Cl} ; 45 \text { to } \\
60)\end{array}$ & $\begin{array}{c}60.1(95 \% \mathrm{Cl} ; 53 \text { to } \\
68)\end{array}$ & $0.003 * *$ & 0.08 \\
\hline
\end{tabular}



VAT (\% of HRR)
$45.90(95 \% \mathrm{Cl} ; 43$
39.45 (95\%Cl; 35.6
to 43.3)
49.77 (95\% Cl; 46.5
$<0.001 * * *$
0.129
VAT (\% of HRmax)
71.58 (95\%Cl; 70.1
to 73.1$)$
69.81 (95\%Cl; 66.9
to 53.0)
0.072
0.029

CPET, cardiopulmonary exercise test. $\mathrm{VO}_{2 \text { Peak, }}$ Peak oxygen consumption. HRmax, maximum heart rate. Bpm, beats per minute. HRR, heart rate reserve. VAT = ventilatory anaerobic threshold. HR, heart rate. ${ }^{*} P<0.05, * * P<0.01,{ }^{* * *} P<0.001$.

$\dagger$, Variables are reported as median (minimum and maximum) values analysed using a non-parametric test. Tr, transformed using $\log _{10}$ transformation and reported as arithmetic mean for meaningful interpretation. 
Table 4. Relation between predicted and measured variables stratified by mode of exercise

\begin{tabular}{|c|c|c|c|c|c|}
\hline & Pooled & Cycle & Treadmill & P-value & $\begin{array}{c}\text { Partial eta- } \\
\text { squared }\end{array}$ \\
\hline $\begin{array}{c}\text { Predicted } \\
\text { HRmax (adjusted } \\
\text { for } \beta \text {-blockade; } \\
\text { bpm) }{ }^{\dagger}\end{array}$ & 136 (118 to 174$)$ & 138 (126 to 174$)$ & 134 (118 to 167$)$ & $0.009 * *$ & \\
\hline $\begin{array}{c}\text { VAT (\% of } \\
\text { predicted } \\
\text { HRmax adjusted } \\
\text { for } \beta \text {-blockade) }\end{array}$ & 67.97 (65.86 to 70.07$)$ & 62.74 (59.68 to 65.80$)$ & 71.10 (68.50 to 73.71$)$ & $\begin{array}{c}<0.001 * \\
*\end{array}$ & 0.131 \\
\hline
\end{tabular}

\section{Predicted HRR} (adjusted for $\beta$ blockade; bpm)

$\begin{array}{ccccc}77.85(95 \% \mathrm{Cl} ; 75.04 \text { to } & 77.93(95 \% \mathrm{Cl} ; 73.19 \text { to } & 77.8(95 \% \mathrm{Cl} ; 74.24 \text { to } & 0.965 & <0.001\end{array}$

VAT (\% of Predicted HRR adjusted for $\beta$ -

\begin{tabular}{cccccc}
\hline $\begin{array}{c}\text { Predicted VO } \\
\left(\mathrm{ml} \cdot \mathrm{min}^{-1}\right)\end{array}$ & $2272.14(95 \% \mathrm{Cl} ;$ & $2258.79(95 \% \mathrm{Cl} ;$ & $2280.35(95 \% \mathrm{Cl} ;$ & 0.815 & $<0.001$ \\
& 2184.11 to 2360.17$)$ & 2114.05 to 2403.53$)$ & 2166.68 to 2394.01$)$ & & \\
& & & & & \\
VO $_{2 \text { peak }}(\%$ of & $87.85(95 \% \mathrm{Cl} ; 84.11$ to & $89.99(95 \% \mathrm{Cl} ; 82.64$ to & $86.56(95 \% \mathrm{Cl} ; 82.40$ to & 0.380 & 0.007 \\
$\begin{array}{c}\text { Predicted } \\
\text { VO }\end{array}$ & $91.58)$ & $97.35)$ & $90.72)$ & & \\
\hline
\end{tabular}

HRmax, maximal heart rate. Bpm, beats per minute. VAT, ventilatory anaerobic threshold. HRR, heart rate reserve. $\mathrm{VO}_{2 \text { peak, }}$ Peak oxygen consumption

${ }^{*} P<0.05,{ }^{* *} P<0.01,{ }^{* * *} P<0.001 .+$, Variables are reported as median (minimum and maximum) values and analysed using a non-parametric test. 

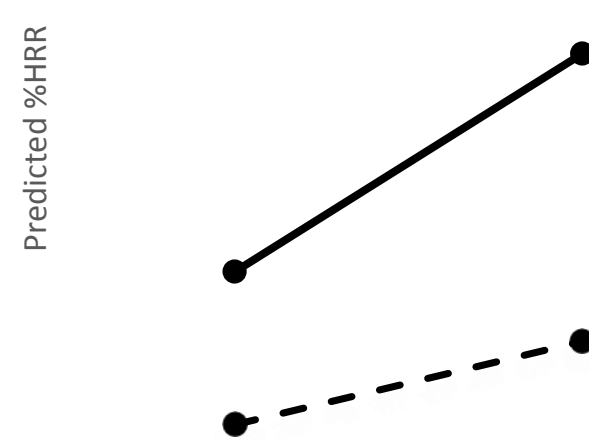
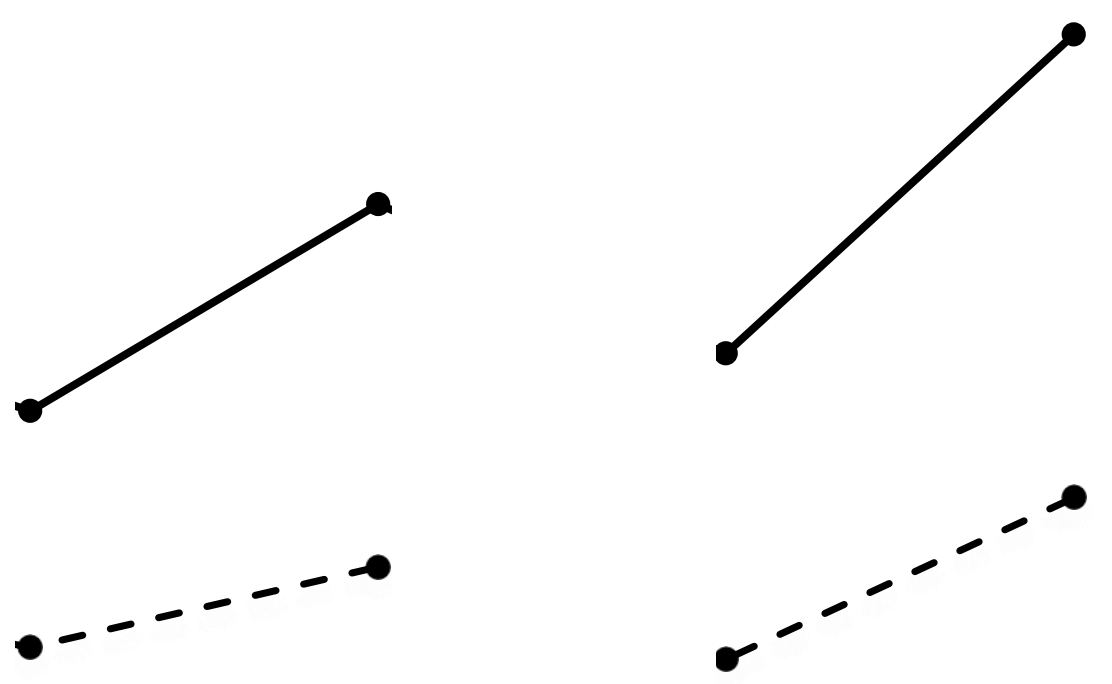

\begin{tabular}{|c|c|c|c|c|c|c|}
\hline & Low Fit & & Mod Fit & & High Fit & \\
\hline Treadmill & 25.9 & 48.6 & 40 & 61.3 & 51.7 & 78.3 \\
\hline - Cycle & 21.6 & 35.7 & 24.7 & 38.3 & 22.7 & 50 \\
\hline
\end{tabular}

Figure 1. Inter-quartile range of VAT identification based on predicted HRR (\% range) in cardiac patients separated by exercise modality and CRF category

Predicted HRR using current guidelines, accounting for beta-blockade. Baseline CRF category based on Taylor et al. (2016); low fit $<5$ METs for women, and $<6$ METs for men, mod fit $5<7 \mathrm{METs}$ for women, and $6<8$ METs for men, high fit $\geq 7$ METs for women, and $\geq 8$ METs for men. VAT, ventilatory anaerobic threshold. HRR, heart rate reserve. MET, metabolic equivalent where $1 \mathrm{MET}=3.5 \mathrm{ml} \cdot \mathrm{kg}^{-1} \cdot \mathrm{min}^{-1}$. 


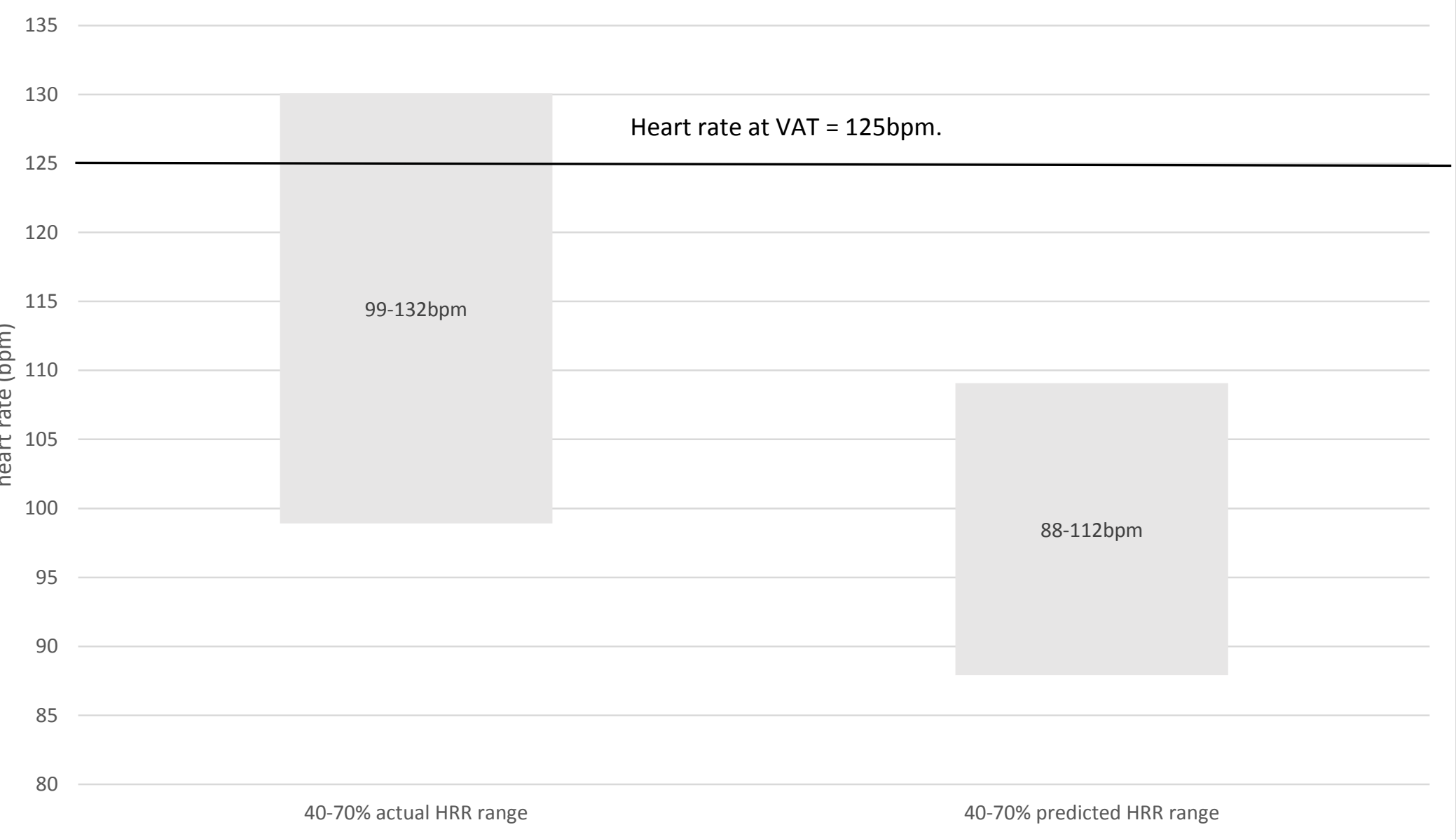

Figure 2a. A case study highlighting how the $40-70 \%$ HRR prediction equation may under-estimate individualised exercise prescription. A 58 year-old male taking beta-blockers with a BMI of 24.8 , VO2peak of $35.28 \mathrm{ml} \cdot \mathrm{kg}^{-1} \cdot \mathrm{min}^{-1}$ in the high fitness category. CPET was conducted on a treadmill. Solid line corresponds to heart rate at ventilatory anaerobic threshold, which is $125 \mathrm{bpm}$. 


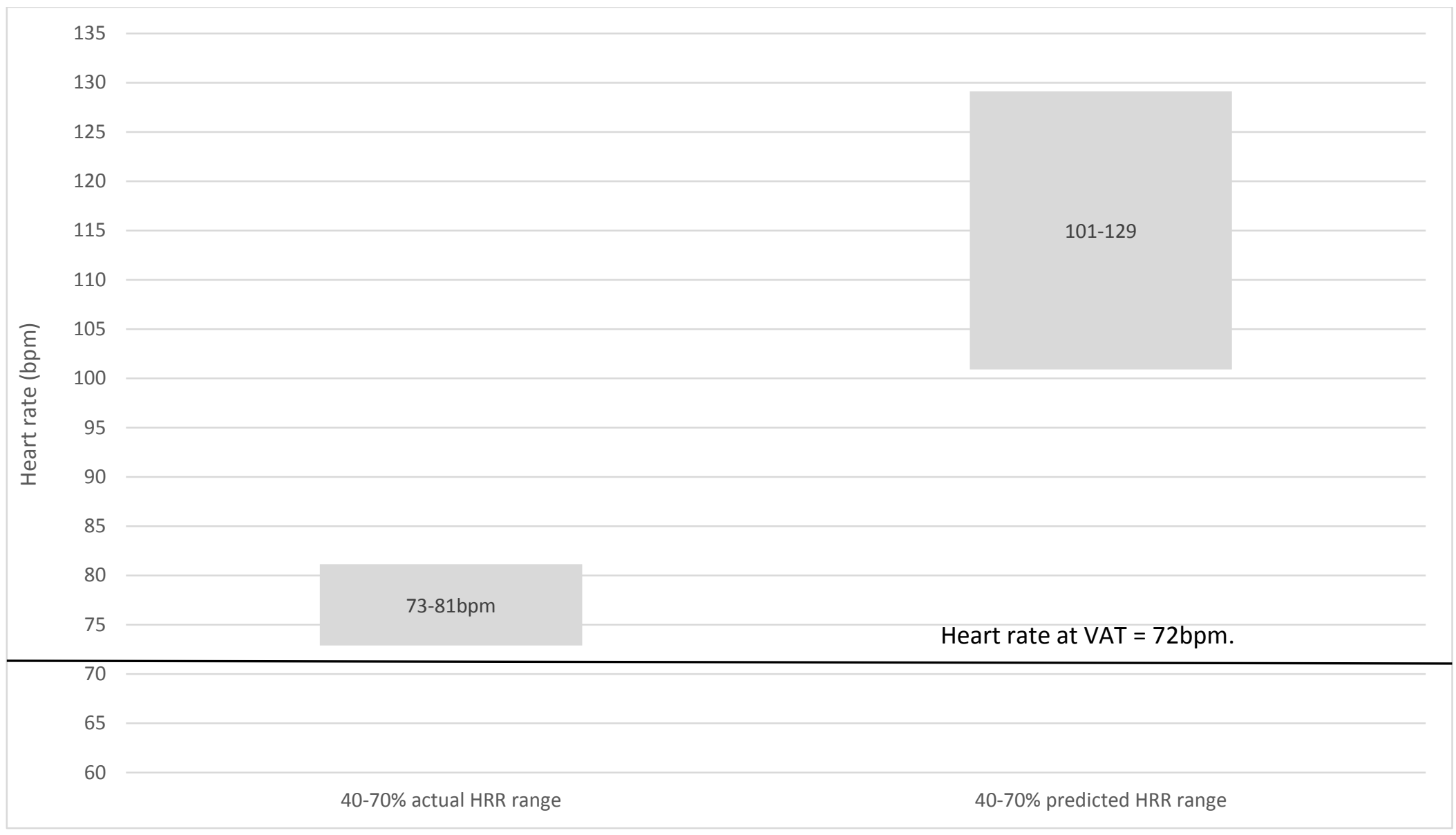

Figure $\mathbf{2 b}$. A case study highlighting how the $40-70 \%$ HRR prediction equation may over-estimate individualised exercise prescription. A 71 year-old male not taking beta-blockers with a BMI of $25.8, \mathrm{VO} 2$ peak of $13.82 \mathrm{ml} \cdot \mathrm{kg}^{-1} \cdot \mathrm{min}^{-1}$ in the low fitness category. CPET was conducted on a cycle. Solid line corresponds to heart rate at ventilatory anaerobic threshold, which is $72 \mathrm{bpm}$. 



\section{JOURNAL CONTRIBUTOR'S PUBLISHING AGREEMENT}

To be completed by the owner of copyright in the Contribution
**Please use Adobe Reader or Adobe Acrobat to complete your agreement. **
Title of Article

Journal

All Author(s)

Corresponding Author

Corr. Author Address
:Application of the Ventilatory Anaerobic Threshold for Optimising Exel

:European Journal of Preventive Cardiology

:Pymer S, Nichols S, Prosser J, Birkett ST, Carroll S, Ingle L

:Prof Lee Ingle

:L.Ingle@hull.ac.uk or 00441482463141 University of Hull, UK

Please read the full terms and conditions on the following pages, then complete, sign and return all pages of this Agreement to the Journal's Editorial Office.

The author who signs this Agreement certifies that he/she is authorised to sign on behalf of him/herself and in the case of a multi-authored Contribution, on behalf of all other authors of the Contribution. The authors understand that they each have the option of signing and returning a separate copy of this Agreement. This Agreement may be signed and executed by e-mail (a scanned hard copy of the Agreement with your signature on it or a digital original copy with your electronic signature are equally acceptable), by traditional hard copy or by fax.

\section{COPYRIGHT ASSIGNMENT}

In consideration for publication in the above Journal, you hereby assign to the owner(s) (the 'Proprietor') of the Journal identified above (the Journal title subject to verification by SAGE Publishing ('SAGE')) copyright in your article ('Article') and the accompanying abstract (all materials collectively referenced as the 'Contribution') prepared by you for the full legal term of copyright and any renewals thereof throughout the world in all languages and in all formats, and through any medium of communication now known or later conceived or developed.

If you or your funder wish your Contribution to be freely available online to non-subscribers immediately upon publication (gold open access), you can opt for it to be included in SAGE Choice, subject to payment of a publication fee. For further information, please visit SAGE Choice.

In the event you provide Supplemental Material to the Proprietor, you hereby grant to the Proprietor the nonexclusive right and licence to produce, publish and make available and to further sub-license the material, in whole or in part, for the full legal term of copyright and any renewals thereof throughout the world in all languages and in all formats, and through any medium of communication now known or later conceived or developed.

By signing this Contributor Agreement you agree both to the above provisions and to the Terms of the Agreement attached below.

Contributor Signature:

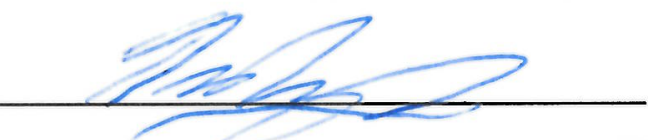

Date signed: 06-03-19

You represent that the Contribution is owned by you unless one of the following is checked:

- *If any author is an employee of the United States Government and prepared the Contribution as part of their official duties, please check here:

US Government Agency Name:

- If any author prepared the Contribution at the direction of their employer, please have a representative of your employer sign below, and please check here: $\square$

Employer Name:

Authorized Signature: Date signed:

*U.S. Government work. If the Contribution was not prepared as part of the Contributor's official duties, it is not a U.S. Government work. If the Contribution was jointly authored, all the co-authors must have been U.S. Government employees at the time they prepared the Contribution in order for it to be a U.S. Government work; if any co-author was not a U.S. Government employee, then the Contribution is not a U.S. Government work. If the Contribution was prepared under a U.S. Government contract or grant, it is not a U.S. Government work - in such case, copyright is usually owned by the contractor or grantee.

If you are required to submit an addendum by your employer or research funding body, please make your request via email to contracts@sagepub.co.uk indicating the name of the Journal and the title of your paper. 
TERMS OF THE AGREEMENT

\begin{abstract}
Warranties.
You warrant to the Proprietor and SAGE that the Contribution is your original work, that you have the full power and authority to enter into this Agreement and to convey the rights granted herein to the Proprietor and to submit the work for first publication in the Journal and that it is not being considered for publication elsewhere and has not already been published elsewhere, either in printed or electronic form, that you have obtained and enclose all necessary permissions for the reproduction of any copyright works not owned by you (including artistic works, e.g. illustrations, photographs, charts, maps, other visual material, etc.) contained in the Contribution and any Supplemental Material you provide and that you have acknowledged the source(s), that the Contribution and any Supplemental Material you provide contain no violation of any existing copyright, other third party rights or any defamatory or untrue statements and do not infringe any rights of others, and you agree to indemnify, defend and hold harmless the Proprietor and SAGE against any claims in respect of any breach of the above warranties. You further agree to be bound by the Terms of the Agreement provided herein as part of this Agreement which outline the circumstances under which the Contribution may be reused.
\end{abstract}

SAGE for its benefit in accordance with the provisions of the Contracts (Rights of Third Parties) Act 1999 hereby asserts its right to the protection of the above warranties and indemnities.

\title{
Declaration of Conflicts of Interest.
}

You certify that:

1. All forms of financial support, including pharmaceutical company support, are acknowledged in the Contribution.

2. Any commercial or financial involvements that might present an appearance of a conflict of interest related to the Contribution are disclosed in the covering letter accompanying the Contribution and all such potential conflicts of interest will be discussed with the Editor as to whether disclosure of this information with the published Contribution is to be made in the Journal.

3. You have not signed an agreement with any sponsor of the research reported in the Contribution that prevents you from publishing both positive and negative results or that forbids you from publishing this research without the prior approval of the sponsor.

4. You have checked in the manuscript submission guidelines whether this Journal requires a Declaration of Conflicts of Interest and complied with the requirements specified where such a policy exists.

It is not expected that the details of financial arrangements should be disclosed. If the Journal does require a Declaration of Conflicts of Interest and no conflicts of interest are declared, the following will be printed with your Contribution: 'None Declared'.

\section{Supplemental Material.}

Supplemental Material includes all material related to the Contribution, but not considered part of the Contribution, provided to the Proprietor by you as the Contributor. Supplemental Material may include but is not limited to datasets, audio-visual interviews including podcasts (audio only) and vodcasts (audio and visual), appendices, and additional text, charts, figures, illustrations, photographs, computer graphics, and film footage. Your grant of a non-exclusive right and licence for these materials to the Proprietor in no way restricts re-publication of Supplemental Material by you or anyone authorised by you.

\section{Publishing Ethics \& Legal Adherence.}

Contributions found to be infringing this Agreement may be subject to withdrawal from publication (see Termination below) and/or be subject to corrective action. The Proprietor (and/or SAGE if SAGE is different than the Proprietor) reserves the right to take action including, but not limited to: publishing an erratum or corrigendum (correction); retracting the Contribution; taking up the matter with the head of department or dean of the author's institution and/or relevant academic bodies or societies; or taking appropriate legal action.

\section{Contributor's Responsibilities with Respect to Third Party Materials.}

You are responsible for: (i) including full attribution for any materials not original to the Contribution; (ii) securing and submitting with the Contribution written permissions for any third party materials allowing publication in all media and all languages throughout the world for the full legal term of copyright; and (iii) making any payments due for such permissions. SAGE is a signatory of the STM Permissions Guidelines, which may be reviewed online. 


\section{Termination.}

The Proprietor and SAGE, together in their abșolute discretion, may determine that the Contribution should not be published in the Journal. If in the rare circumstance the decision is made not to publish the Contribution after accepting it for publication, then all rights in the Contribution granted to the Proprietor shall revert to you and this Agreement shall be of no further force and effect, and neither you nor the Proprietor nor SAGE will have any obligation to the other with respect to the Contribution.

\section{General Provisions.}

This Agreement shall be deemed to be a contract made in England and shall be construed and applied in all respects in accordance with English law and,fie parties submit and agree to the jurisdiction of the English courts.

This Agreement may be executed in eounterparts each of which shall be deemed the original, all of which together shall constitute one and the same Agrees sint A faxed copy or other electronic copy shall be deemed as an original. This transaction may be conducted by bectedo means and the parties authorize that their electronic signatures act as their legal signatures of this Agreement 1 Agreement will be considered signed by a party when their electronic signature is transmitted. Such-signature shat betreated in all respects as having the same effect as an original handwritten signature. (You are notrequîtred to conduct this transaction by electronic means or use an electronic signature, but if you do so, then you the give, your authorization pursuant to this paragraph.)

No amendment or modification of any provision of this Agreement shall be valid or binding unless made in writing and signed by all parties.

This Agreement constitutes the entire agreement between the parties with respect to its subject matter, and supersedes all prior and contemporaneous agreements, understandings and representations. The invalidity or unenforceability of any particular provision of this Agreement shall not affect the other provisions, and this Agreement shall be construed in all respects as if any invalid or unenforceable provision were omitted.

If any difference shall arise between you and the Proprietor touching the meaning of this Agreement or the rights and liabilities of the parties thereto, the same shall be referred to the arbitration of two persons (one to be named by each party) or their mutually agreed umpire, in accordance with the provision of the England Arbitration Act 1996 or any amending or substituted statute for the time being in force.

\section{Consent for Commercial Electronic Messages.}

You hereby provide your express consent for the Proprietor, its affiliates and licensees (expressly including SAGE, where SAGE is not the Proprietor), and their respective designees to contact you in connection with any business communication or other correspondence. The parties agree that such consent may be withdrawn by you at a later time by providing written notice (including by email) to the Proprietor (and/or SAGE if different than the Proprietor). This clause shall survive expiration or earlier termination of this Agreement.

For more information on copyright and permissions and SAGE's publishing policies (including Ethics \& Responsibility), please visit the SAGE Journal Author Gateway: https://uk.sagepub.com/en-gb/eur/page/journal-author-gateway

SAGE will provide the Corresponding Author of the Contribution with an electronic copy of the Contribution. For information about how you may re-use the Contribution, please consult SAGE Journals Permissions:

https://uk.sagepub.com/en-gb/eur/journals-permissions

All commercial re-use of the published Contribution should be referred to SAGE. 


\author{
Click here to access/download
Author Responsibility Form
ejpc_authorship_responsibility_form.docx \\ Click here to access/download
Author Responsibility Form
ejpc_authorship_responsibility_form.docx \\ Click here to access/download
Author Responsibility Form
ejpc_authorship_responsibility_form.docx

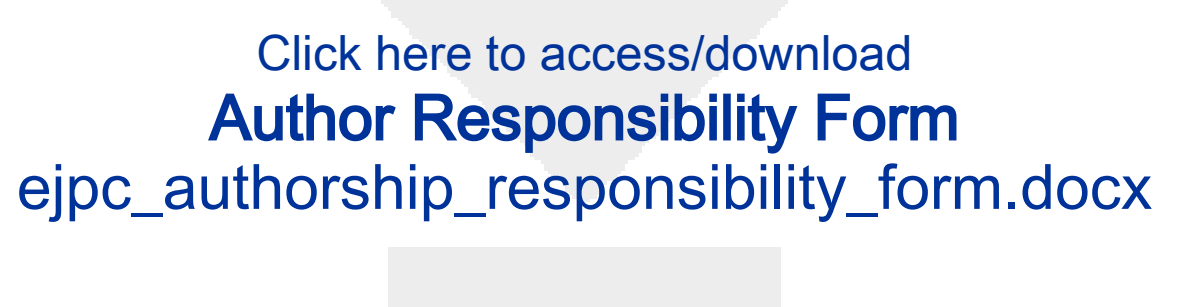

Aut

(n)

Author Responsibility Form

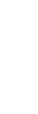

(1)

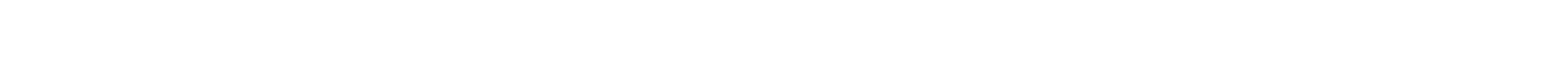

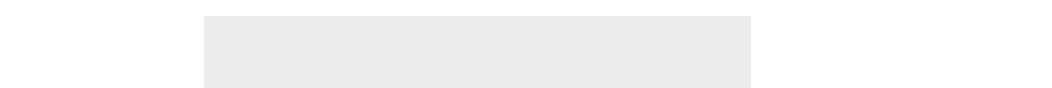

